\title{
Mechanical, Pure Fatigue and Corrosion Fatigue Properties of Pack Carburizing Low Carbon Steel Aisi 1020 by Using Waste Organic Materials in 3.5\% $\mathrm{Nacl}$
}

\author{
Kharia Salman Hassan \\ middle technical university \\ Ahmed Ibrahim Razooqi ( $\sim$ ahmedtcb@mtu.edu.iq ) \\ Middle technical University iraq https://orcid.org/0000-0001-7989-0808 \\ Munaf Hashim Ridha \\ middle technical university
}

Original Article

Keywords: Corrosion fatigue, Pack carburizing ,Low carbone steel 1020

Posted Date: June 24th, 2020

DOI: https://doi.org/10.21203/rs.3.rs-28892/v1

License: (c) (i) This work is licensed under a Creative Commons Attribution 4.0 International License.

Read Full License 


\section{Abstract}

The influence of pack carburizing by different leftover organic materials was studied.Egg shell, dropping flower,orang shell mixed with charcoal, was used as refresher and its effect on corrosion fatigue of low carbon steel 1020 AISI (American Iron and Steel Institute) was studied. Carbon steel 1020 originally used for manufacturenumerousdevice parts such as gears, shaft, connecting rod.Severalsamples for the tensile and fatigueexaminationsareequipped from the based metalagreeing toASTM (American Society for Testing and Materials)descriptions. Pack carburizing is carried outby charcoal for liberation atomic carbon. The diffusion procedure on selectedsamples were pack carburizing using charcoal with addition leftover organic materialsas energies withratio of $30 \%$ pack carburizing and at 925 for two hours. After that, the samples quenched in water and tempered. Tensile,hardness, microstructures examination were implemented. Corrosion fatigue wascarried by rotating bending device in sea water $3.5 \% \mathrm{NaCl}$. The results showed that all carburizing compound causes an improving in corrosion fatigue due to the change in microstructure between the surface of specimens,its core and the comparative residual stress which produce by carburizing process.Egg shell give the high value and charcoal the lower value with respect to the basemetal.

\section{Introduction}

Several types of machines such as ships, drills, and underwater pipelines, were exposed to marine. Therefore corrosion is likely to happen in these machines. Most of machine parts are manufactured from Carbon and alloy steels. Although steel are sensitive to corrosion but, it is commonly used due to its low cost, and easiness of manufacture. On the other hand, corrosion can increase the possibility of failure due to fatigue. Therefore, corrosion needs be taken into account in engineering design [1]. Fatigue can be defined as the failure that happened because of repetitive stresses and it can affect any part or component that moves. Corrosion fatigue work under combined action of cyclic loading and corrosion[2], [3].

Corrosion is a failure which occur in varies metals because of a chemical or electrochemical interact with its medium. Essentially, corrosion happened because of the environment and it does not affected by the stress. Several actions were done in order to avoid the interaction between metal and the surrounding. It is obvious that the relations between corrosion and fatigue can dramatically increase the crack length and propagate the cracks in a fast way which leads to increase the opportunity of fatigue in air only [4], [5]. The fatigue strength can be improved using surface heat treatment methods as carburizing, nitriding, which encourage a residual compressive stresses that minimize the harmful influence of the residual tensile stresses. Pack carburizing is the case hardening methods, which are carry out to change the surface and structure qualities of the production machineries. This process increase the steel hardness, by way of modifying the chemical composition of the steel surface [6]. Many factors such as process temperature, time, cooling medium and carburizing media affect the pack carburizing. To increase speed of the method and to rise the carbon, "energizer" such as $\mathrm{Na}_{2} \mathrm{CO}_{3}, \mathrm{CaCO}_{3}$ or $\mathrm{BaCO}_{3}$ were used [6] with quantity ranging from $0-40 \%$. The procedure is done by exposing the part to carbon rich atmosphere at 
the austenite temperature (850-9500C). Carbon sources for pack carburizing were investigated by some investigators as a stimulating subject. This is due to carbon from diverse reference having diverse diffusion characteristics [7]. P. Negara et al. [8] studied the pack Carburizing using energizer $\left(\mathrm{BaCO}_{3}\right)$ with goat bone charcoal and bamboo charcoal with five different compositions. The test results show that Carburizer composition of $20 \% \mathrm{BaCO}_{3}+80 \%$ goat bone charcoal give the maximum hardness 789.273 $\mathrm{HV}$ at $0.2 \mathrm{~mm}$ from the surface. The highest effective case depth of $1 \mathrm{~mm}$ was obtained by carburizer composition of $20 \% \mathrm{BaCO}_{3}+60 \%$ goat bone charcoal $+20 \%$ bamboo charcoal. As a result, the base structures ferrite and pearlite was changeed to hard martensite in the surface after pack carburizing. Ihom et al. [9] improved the hardness of cast mild steel by pack carburizing in arecaceae flower dropping. It is observed that arecaceae flower droppings improve the surface hardness of mild steel parts compared to wood charcoal and cow bone charcoal are potential carbon sources. Ihom et al. [10] used organic materials like sugar cane, rice husks, egg shell, melon shell, arecaceae flower droppings, plastics, polyethylene, and charcoal as carbon sources. They found that the waste organic materials showed improvement in the hardness values of the mild steel specimens over the $30 \mathrm{HRC}$ hardness value of the untreated mild steel specimen Furthermore, goat bone charcoal and bamboo charcoal are used as alternative of carbon sources. Al-Sultani et al. [11] studied the inhibitive quality of natural production with spearmint plant remove as environmentally friendly corrosion inhibitor for low carbon steel in $(3.5 \% \mathrm{NaCl})$ solution. The test results show that the immersion model in $(3.5 \% \mathrm{NaCl})$ solution contains the inhibitor with concentration of ( $15 \%$ in volume). As a result, the decrease in weight show that it gain a layer of adequate oxide on the surface of steel. Further, the amount of loss weight decrease with increasing concentration of inhibitor. Okorokov et al. [12] the influence of compressive remaining stress on the corrosion fatigue life of a low carbon steel was studied. A novel point of calculating the effect of compressive remaining stresses on the fatigue life depending on challenging of the dual nicked specimens is suggested. The effect of compressive remaining stresses on corrosion fatigue life had been evaluated through tests on standard and double notch tests specimens in air and tap water environments. Uniaxial fatigue examinations on typical samples with different loading proportions revealed important reduction in fatigue life in the water surroundings. It's aimed in this research to improve corrosion fatigue of low carbon steel 1020 that used to manufacture gears, shaft, connecting rod, in the marine industry.

\section{Materials}

Low carbon steel 1020 AISI which used in many steel components such as cams, gears and shafts is select. Chemical analysis was done by (Thermo arl 3460, optical emission spectrometer). The obtained results, which is similar to the American standard, are listed in table (1).

Table (1) Chemical composition of the low carbon steel 1020 AISI. 


\begin{tabular}{|c|c|c|c|c|c|c|c|}
\hline Wt\% of element & C & Si & Mn & $\mathrm{Cr}$ & Mo & $\mathrm{Cu}$ & Co \\
\hline Actual value $\%$ & 0.2 & 0.009 & 0.65 & 0.011 & 0.004 & 0.041 & 0.004 \\
\hline Standard value \% & $0.18-0.23$ & 0.01 & $0.3-0.6$ & - & - & - & - \\
\hline $\mathrm{Wt} \%$ of element & $\mathrm{V}$ & W & $\mathrm{Ai}$ & $\mathrm{Ni}$ & $\mathrm{P}$ & S & \\
\hline Actual value $\%$ & 0.0009 & 0.003 & 0.001 & 0.012 & 0.09 & 0.05 & \\
\hline Standard value \% & - & - & - & - & 0.04 & 0.05 & \\
\hline
\end{tabular}

\section{Exprements}

\section{Preparation of Specimens}

Several samples for tensile test are manufactured by programmable CNC lathe machine according to ASTM 176000, as shown in figure (1). The obtained results, which is similar to the American standard, are listed in table (2).

Table (2) Standard Mechanical properties of 1020 AISI

\begin{tabular}{|ll|}
\hline Properties & Value \\
\hline Density $\left(1000 \mathrm{Kg} / \mathrm{m}^{3}\right)$ & $7.7-8.03$ \\
\hline Poison's ratio & $0.27-0.3$ \\
\hline Elastic Modulus (GPa) & $190-210$ \\
\hline Tensile strength (MPa) & 394.7 \\
\hline Yield strength (MPa) & 294.8 \\
\hline Elongation (\%) & 36.5 \\
\hline Hardness (HB) & 111 \\
\hline Impact strength (J) (Izod) & 123.4 \\
\hline
\end{tabular}

Also the many samples of fatigue test manufactured according to DIN 50113, that shown in Figure (2).

\section{Samples classification.}

The specimens are classified as in table (3).

Table (3) Classification of samples 


\begin{tabular}{|ll|}
\hline Symbol & Conditions \\
\hline A & As received \\
\hline B & Carburized by charcoal alone \\
\hline C & Carburized charcoal $+30 \%$ powder of sell egg \\
\hline D & Carburized charcoal $+30 \%$ powder of orang shell \\
\hline E & Carburized charcoal $+30 \%$ powder of dropping flower shell \\
\hline
\end{tabular}

\section{Carburization of Mild Steel Samples.}

The pack carbonization process was carried out by charcoal. The samples were exposed to $925^{\circ} \mathrm{C}$ for two hours and then the oven was turned off for cooling. The process was repeated for other samples using other mediums as the orange peel, egg shell and flower dropping which are collected, drying and grinding. Each one of these medium was mixed with charcoal at percentage of $30 \%$ for each one as activator.

\section{Heat treatment after carburizing process.}

After the carburization process heat treatment was carried out by the procedure below:

1-Quenching process: It includes heating the specimens to $850^{\circ} \mathrm{C}$ for half hour and suddenly immersed in a cooling medium bath water. Essentially, the hardness in steel influenced by quenching rate,

2-Tempering process: the carburized steel samples were heated to the temperature of $150{ }^{\circ} \mathrm{C}$ for one hour then cooled by air to get rid of the residual stresses and decrease brittleness.

\section{Microstructures test.}

For microstructure test, the samples are exposed to the following procedure

1-The samples were grinded with emery papers with $\operatorname{grad}(240,320,500,800,1000$, and 1200).

2-The samples were polished using special cloth with auxiliary of $\mathrm{Al}_{2} \mathrm{O}_{3}$ solution of grain size of $0.5 \mu \mathrm{m}$.

3-Etching process is done by immersing each sample in etching solution (nital solution) which consists of $98 \%$ Methyl alcohol and $2 \%$ Nitric acid for $30 \mathrm{sec}$. Then the sample is washed with water and alcohol and dried in oven.

4-Microstructures of samples are inspected with optical microscope supply with computer and digital camera, microstructure photos are shown in figure (3).

\section{Hardness test}




\section{macro hardness}

Hardness examination was carried out on all samples by using vickers hardness method at $50 \mathrm{Kg}$ load, the results are shown in Figure (4), the (d) average values of three readings are recorded for each specimen then hardness was calculated as follow:

$$
\mathrm{HV}=1.854 p /\left(\bar{d}^{\wedge} 2\right) \ldots . .(1) \quad[15]
$$

Where $\left({ }^{p}\right)$ : is the applied load in $\mathrm{kg}, \quad(\mathrm{d})$ : was penetration diameter in $\mathrm{mm}$

\section{micro hardness}

The vickers hardness device, with a 500gf weight with a load holding time of 15 secondsis implemented.The hardness was measured across the carburizing surfacefor distance of $3 \mathrm{~mm}$ towards the middleat $0.25 \mathrm{~mm}$ from the edge end. The results were illustrated infigure (5).

\section{Carburizing depth}

The effective way technique to measure case depth by visually examining a part's cross section under microscopes. Applying nital to the cross section prior to measurement creates the visual contrast humans need to be able to distinguish the part's case from its core. The carbon depth of all specimens shown in figure (6).

\section{Surface roughness}

The average value of the free surface roughness, was measured at the surface area of all specimens and it indicated by the parameter Ra which is the center-line average of adjacent peaks measured by using pertho meter (s6p) all results shown infigure(7).

\section{Tensile test}

Tensilequalities aremeasured at room temperature by means of the computerized Tonus olsen universal tensile testing machine. All tensile experimentsareimplement at a constant crosshead speed of 10 $\mathrm{mm} / \mathrm{min}$. The rate of three specimens was calculated to assess the tensile property of each specimen. The test results are shown in table (4). 
Table 4

mechanical results for all specimens.

\begin{tabular}{|llllll|}
\hline Sample & $\begin{array}{l}\sigma_{u} \text { Ultimate } \\
\text { stressMPa }\end{array}$ & $\begin{array}{l}\sigma_{\mathrm{y}} \text { Yield stress } \\
\mathrm{MPa}\end{array}$ & $\begin{array}{l}\text { Elongation } \\
\%\end{array}$ & $\begin{array}{l}\text { Dry } \\
\text { fatigue } \\
\text { limit } \sigma_{\mathrm{f}}\end{array}$ & $\begin{array}{l}\text { Corrosion fatigue } \\
\text { limit } \sigma_{\mathrm{f}} \mathrm{MPa}\end{array}$ \\
\hline $\mathrm{A}$ & 423 & 394 & 18 & 210 & 140 \\
\hline B & 727 & - & 16 & 360 & 290 \\
\hline C & 1239 & - & 8 & 615 & 450 \\
\hline D & 1106 & - & 10 & 553 & 400 \\
\hline E & 1156 & - & 9 & 578 & 420 \\
\hline
\end{tabular}

\section{Dry fatigue examination}

A fatigue-testing device of type (Schenckpunn)was used to carry out a rotating bending to all dry and corrosion fatigue specimenswhich is subjected to load from the right side of the vertical to the axis of specimen to develop a bending moment. Therefore, the surface of the specimen is under tension and compression stresses when it rotates.

The bending stress ( ${ }^{\sigma_{\mathrm{b}}}$ ) is computedby the relation in equation (2)

$$
\sigma_{b}=\frac{p * L * 32}{\pi * \mathrm{~d}^{\wedge} 3} \ldots \ldots . \text { (2) [15] }
$$

Where $P$ is the load measured in Newton $(N)$, and $(L)$ the force arm is equal to $125.7 \mathrm{~mm}$ and (d)is the minimum diameter of the specimen in $\mathrm{mm}$.

The behavior is described by the S-N curve figure(8) as follows for all specimens .

Figure (8) S-N Curved for dry fatigue.

The dry fatigue limit equations of all specimens are listed in table(5)

Table 5

The dry fatigue limit and equations 


\begin{tabular}{|lll|}
\hline Specimens symbol & Fatigue limit at $(10)^{7}$ cycle in MPa & S-N curve Equation \\
\hline A & 210 & $\mathrm{~S}_{\mathrm{f}}=1828.549 \mathrm{~N}_{\mathrm{f}}^{-0.13513878}$ \\
\hline B & 360 & $\mathrm{~S}_{\mathrm{f}}=1471.0643 \mathrm{~N}_{\mathrm{f}}^{-0.089455301}$ \\
\hline C & 615 & $\mathrm{~S}_{\mathrm{f}}=1722.6567 \mathrm{~N}_{\mathrm{f}}^{-0.067068413}$ \\
\hline E & 553 & $\mathrm{~S}_{\mathrm{f}}=1798.1164 \mathrm{~N}_{\mathrm{f}}^{-0.075192935}$ \\
\hline
\end{tabular}

\section{Corrosion fatigue test:}

Corrosion fatigue examination is similar to the examination in dry fatigue but it is performedin sea water $3.5 \% \mathrm{NaCl}$ at $6.7 \mathrm{PH}$. This solution is put in corrosion system which is equipped for apply the fatigue corrosion examination as revealed in figure (9).

The fatigue corrosion limit equations of specimens are listed below in table(6):

Table 6

The fatigue corrosion limit and equations

\begin{tabular}{|lll|}
\hline Specimens symbol & Fatigue limitat $(10)^{7}$ cycle in MPa & S-N curve equation \\
\hline A & 140 & $\mathrm{~S}_{\mathrm{f}}=1595.0965 \mathrm{~N}_{\mathrm{f}}^{-0.15186801}$ \\
\hline B & 290 & $\mathrm{~S}_{\mathrm{f}}=1866.76 \mathrm{~N}_{\mathrm{f}}^{-0.1224576}$ \\
\hline D & 450 & $\mathrm{~S}_{\mathrm{f}}=1537.5443 \mathrm{~N}_{\mathrm{f}}^{-0.078551026}$ \\
E & 400 & $\mathrm{~S}_{\mathrm{f}}=1377.7488 \mathrm{~N}_{\mathrm{f}}^{-0.082090335}$ \\
\hline
\end{tabular}

\section{Results And Discussion}

The microstructure of the low carbon steels, represented by the samples of group (A) was shown in figure (3). Obviously, the particles of the ferrite and perlite phases is clear and it causes decreases in 
mechanical properties and corrosion resistance. Also, from figure (3B,C,D,E), the samples (B) which exposed to pack carburizing by charcoal, contain iron carbide which it formed on the surface specimen as a surface layer at a certain depth. For samples of group (C), it was noted that cementite and martensite existed on the surface layer in large depth due the high rate of calcium carbonate in shell eggs, which caused an increase in surface hardness and strength. For samples $(E)$, the predominant phase is white cement and martensite. Additionally, samples of group (D) have cementite martensite and all organic residues using as energies for pack carburizing contributed to the generation of the hard surface layer at different depths, figure (6). The egg shells gave the highest depth due to the high percentage of calcium and the orange gave the lowest values. Mechanical characteristic like strength and ductility were determined by tensile examination of the all specimens, figure (5). It is obvious that all the mechanical properties were enhanced after pack carbonizing with different organics. S-N curve for the base metal and the other metals was illustrated in figure (8). It is clear from the figure that all samples show enhancement in fatigue limits compared to the base metal. The layer of pack carbonizing increases the tensile strength and as a result of that the fatigue limits increase. This behavior can be attributed to the comparative stresses at the surface. Also this layer delays the fatigue flaw from starting. Typically, the crack incipience at the grain of ferrite and propagate quickly but it stops at the Pearlite granule. On the contrary, the crack does not start at perlite granule as shown in figure (3A). S-N curve for all specimens for fatigue corrosion test is shown in figure (10). It is recognized that the relations between corrosion and fatigue can dramatically increase the crack propagation length in a fast way and it decrease the fatigue limits compared to the samples tested in air only. This behavior can be attributed to the formation of the inclusion in the surface which leads to increase the possibility of crack formation. Additionally, the load plays a vital role in increasing the crack propagation. Therefore, using Pack carburizing techniques in all media improve the fatigue life comparing with base metal. The results of the current findings agreed well with [5], [13], [14].

\section{Conclusions}

This paper investigate the effect of compressive residual stress which produced by pack carburizing at different organic media and at dry and corrosion fatigue life of a low carbon steel. The effect of compressive residual stresses on corrosion fatigue life has been evaluated during examinations in air and sea water surroundings. Uniaxial fatigue tests on base metal at different load reveal important reduction in fatigue life in the sea water surroundings at $65 \%$. This decay in fatigue life is improved by packed carburizing in diffident percentage. The shell egg give the highest percentage by $29 \%$, for dry fatigue and $32 \%$ for corrosion fatigue compared with base metal. Also, charcoal fatigue life increase by $17 \%$ and $20 \%$ for dry and corrosion fatigue respectively.

\section{References}

1. A. P. Ihom, G. B. Nyior, M. U. Suleiman, and G. Z. Ibrahim, "Improving surface hardness of steel using rice husk waste," Niger. J. Trop. Eng., 2011. 
2. P. Aondona, "The efficacy of carburizing compounds with different carbon source and added industrial energizers for surface treatment of mild steel for mechanical property improvement," MOJABB, vol. 2, no. 2, 2018.

3. S. R. Nimbhorkar and B. D. Deshmukh, "Effect of case hardening treatment on the structure and properties of automobile gears," Int J Mod Eng Res, vol. 3, no. 2, pp. 637-641, 2013.

4. R. Mohammed, Dilkush, G. M. Reddy, and K. S. Rao, "Comparative Studies on microstructure, mechanical and corrosion behaviour of DMR 249A Steel and its welds," IOP Conf. Ser. Mater. Sci. Eng., vol. 330, p. 012018, Mar. 2018.

5. F. Menan and G. Henaff, "Influence of frequency and exposure to a saline solution on the corrosion fatigue crack growth behavior of the aluminum alloy 2024," Int. J. Fatigue, vol. 31, no. 11-12, pp. 1684-1695, 2009.

6. H. Elzanaty, "Effect of carburization on the mechanical properties of the mild steel," Int. J. Innov. Appl. Stud., vol. 6, no. 4, p. 987, 2014.

7. S. A. Afolalu, S. B. Adejuyigbe, O. R. Adetunji, and O. I. Olusola, "EFFECTS OF CARBURIZATION ON MECHANICAL PROPERTIES OF RECYCLED STEEL WITH PERM KERNEL SHELL (PKS) AS CARBON ADDITIVES.," Int. J. Adv. Res., vol. 3, no. 5, pp. 1-7, 2015.

8. P. Negara et al., "Hardness Distribution and Effective Case Depth of Low Carbon Steel After Pack Carburizing Process under Different Carburizer," in Applied Mechanics and Materials, 2015, vol. 776, pp. 201-207.

9. A. P. Ihom, G. B. Nyior, M. Ambayin, and M. Eng, "'Surface Hardness Improvement of Mild Carbon Steel using Arecaceae Waste Flower Droppings," Pac. J. Sci. Technol. 13, vol. 1, 2012.

10. A. P. Ihom, G. B. Nyior, O. O. Alabi, S. Segun, I. J. Nor, and J. N. Ogbodo, "The potentials of waste organic materials for surface hardness improvement of mild steel," Int J Sci Eng Res, vol. 3, no. 11, pp. 1-20, 2012.

11. K. F. Al-Sultani, F. A. Al-Seroury, and A. A. Shaymaa, "Effect of a New Organic Inhibitor for Carbon Steel in Salt Solution," in Applied Mechanics and Materials, 2013, vol. 420, pp. 215-221.

12. V. Okorokov, M. Morgantini, Y. Gorash, T. Comlekci, D. Mackenzie, and R. van Rijswick, "Corrosion fatigue of low carbon steel under compressive residual stress field," Procedia Eng., vol. 213, pp. 674$681,2018$.

13. M. A. Abdulrazzaq, "Investigation The Mechanical Properties of Carburized Low Carbon Steel," Int. J. Eng. Res. Appl., vol. 6, no. 9, pp. 59-65, 2016.

14. Mohamed Waheed, "The Effect of Some Surface Treatments of Carbon Steel on fatigue Behavior," University of Technology, Iraq, 1995.

15. W. D. Callister Jr and D. G. Rethwisch, Fundamentals of materials science and engineering: an integrated approach: John Wiley \& Sons, 2012.

\section{Figures}




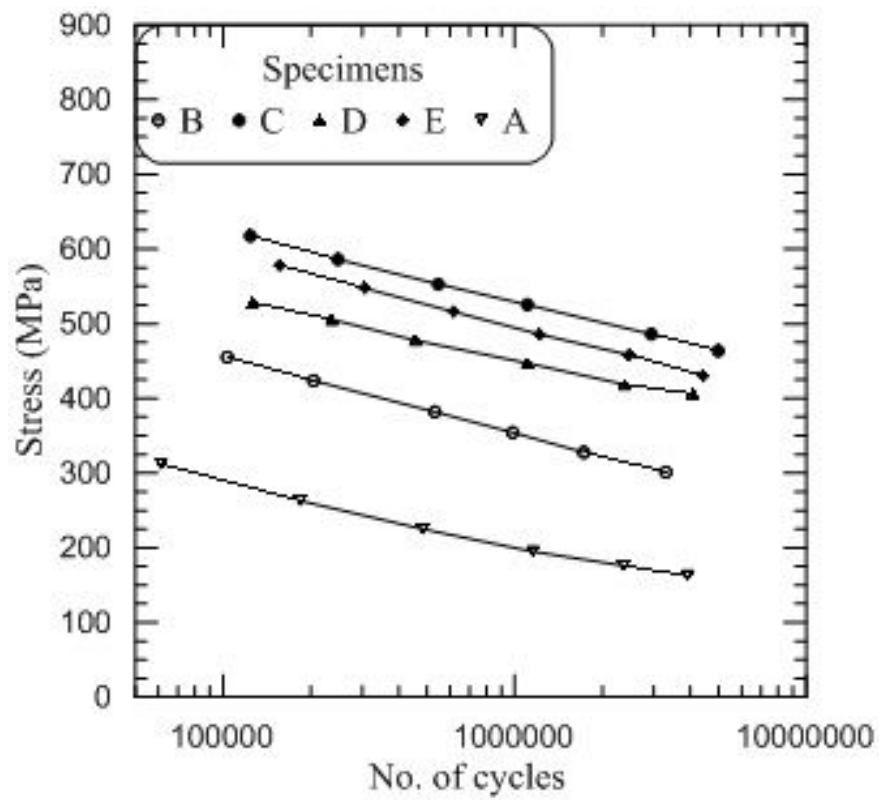

Figure 1

S-N Curved for corrosion fatigue.

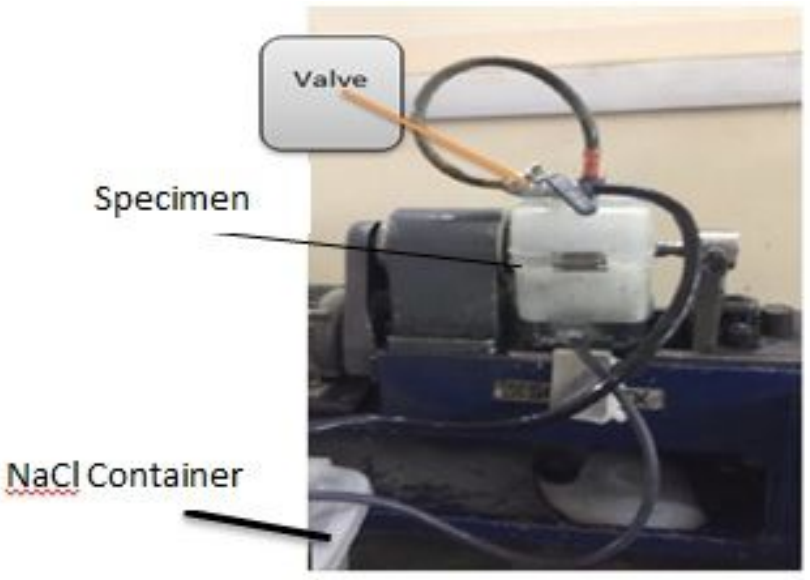

Figure 2

corrosion fatigue assembly. 


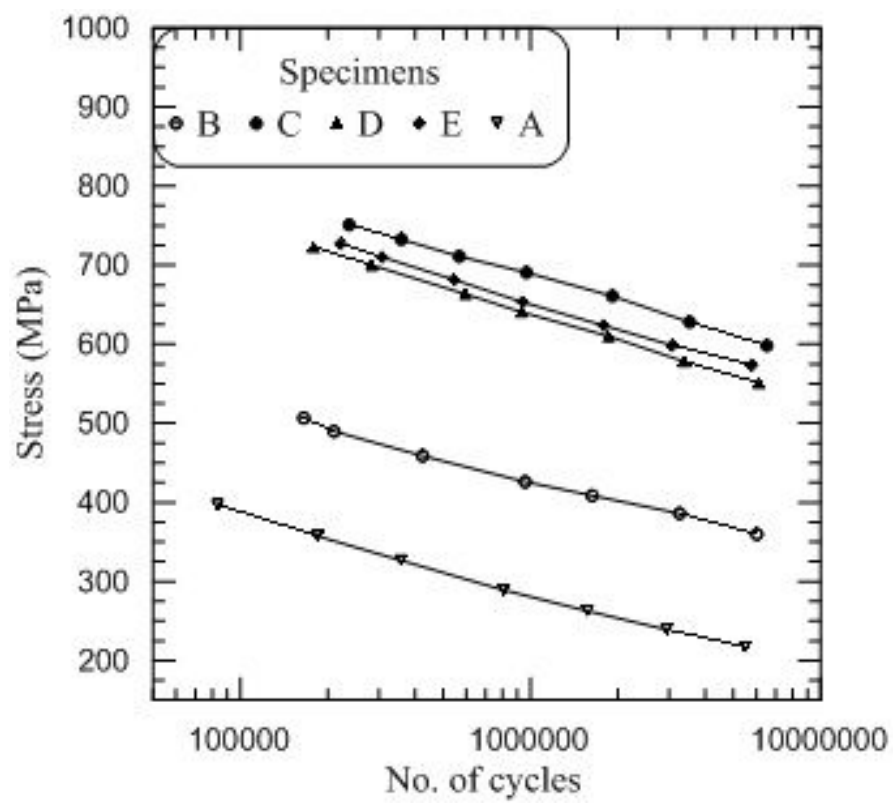

Figure 3

S-N Curved for dry fatigue.

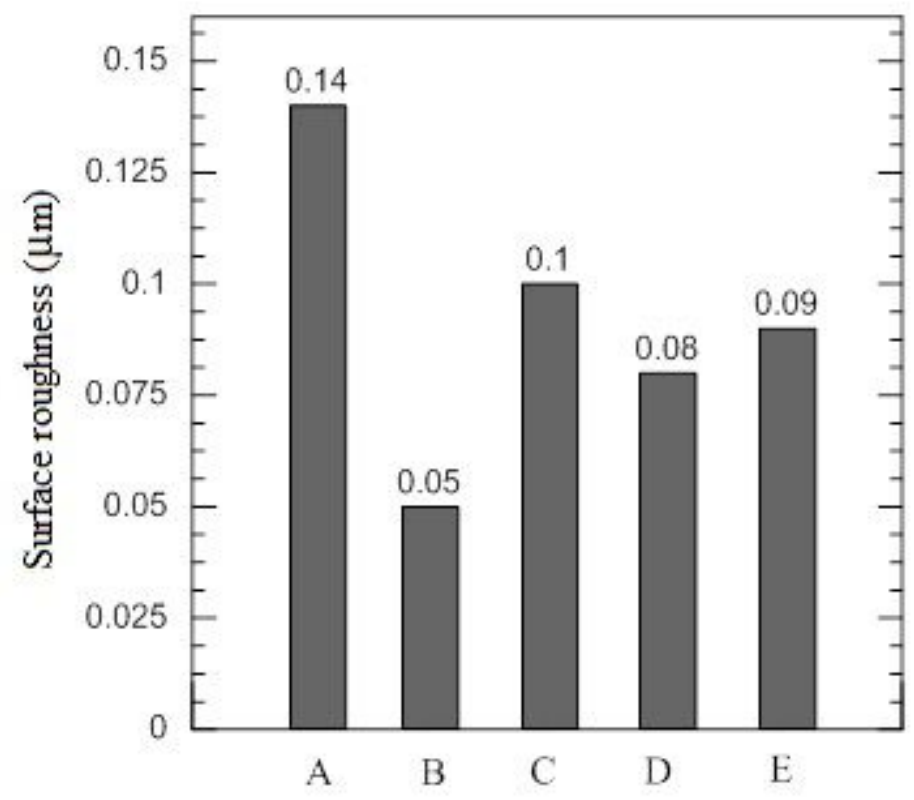

Figure 4

Surface roughness results for all specimens. 


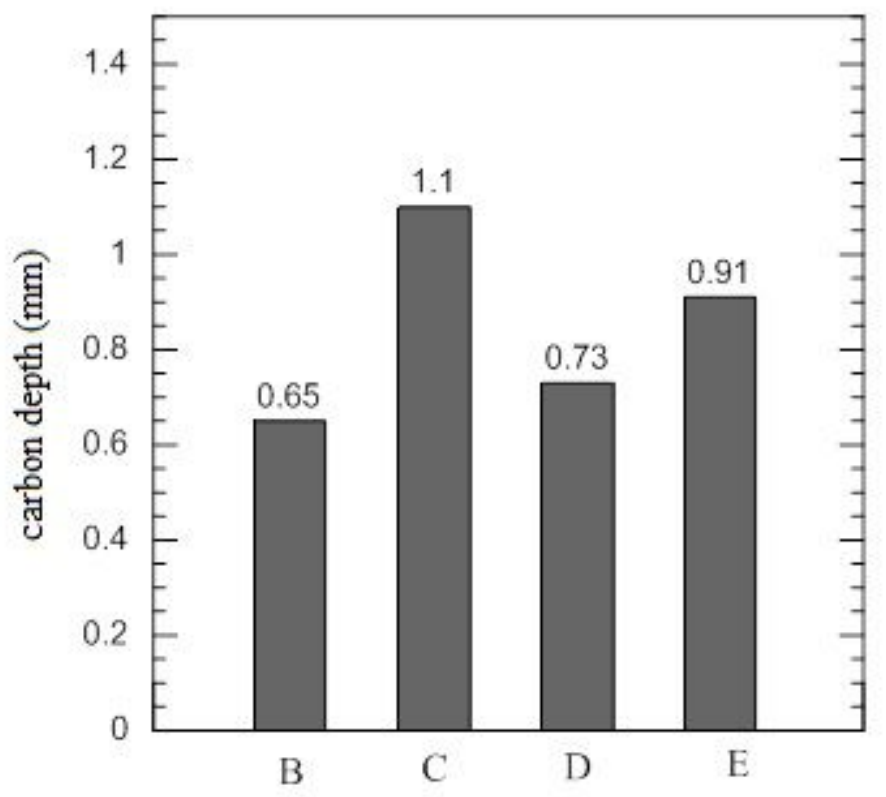

Figure 5

depth carburizing for all specimens.

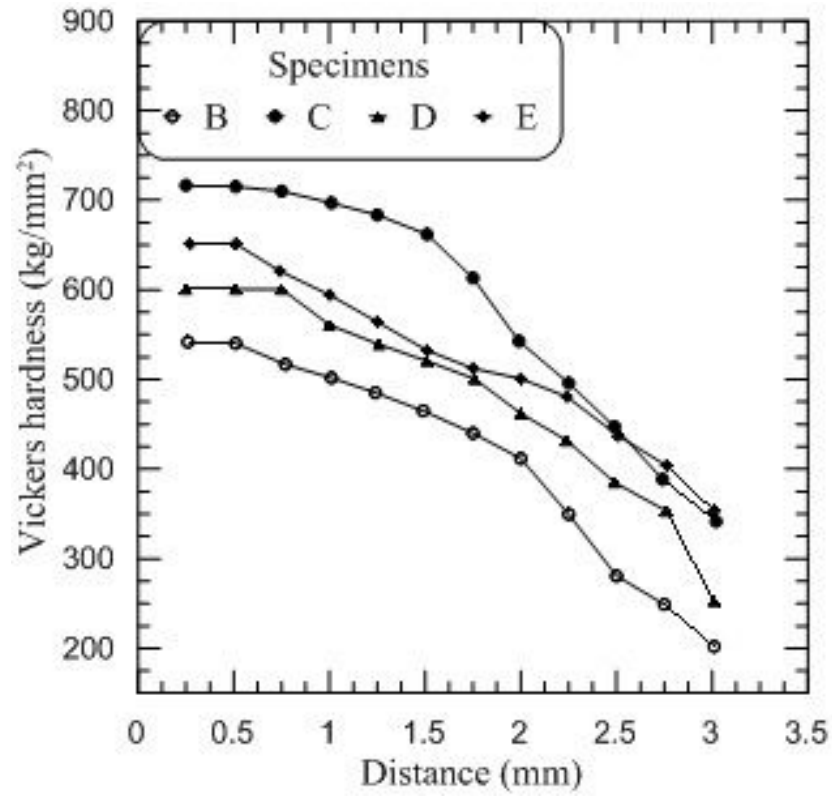

Figure 6

Micro hardness results for all carburized specimens. 


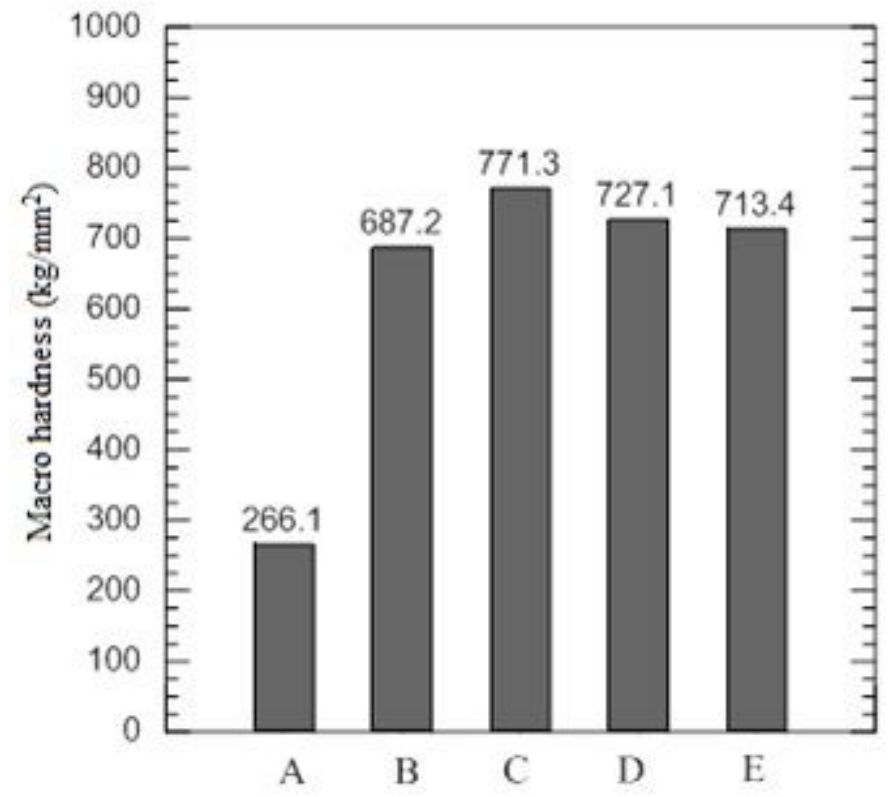

Figure 7

Macro hardness result for all specimens in table (3)
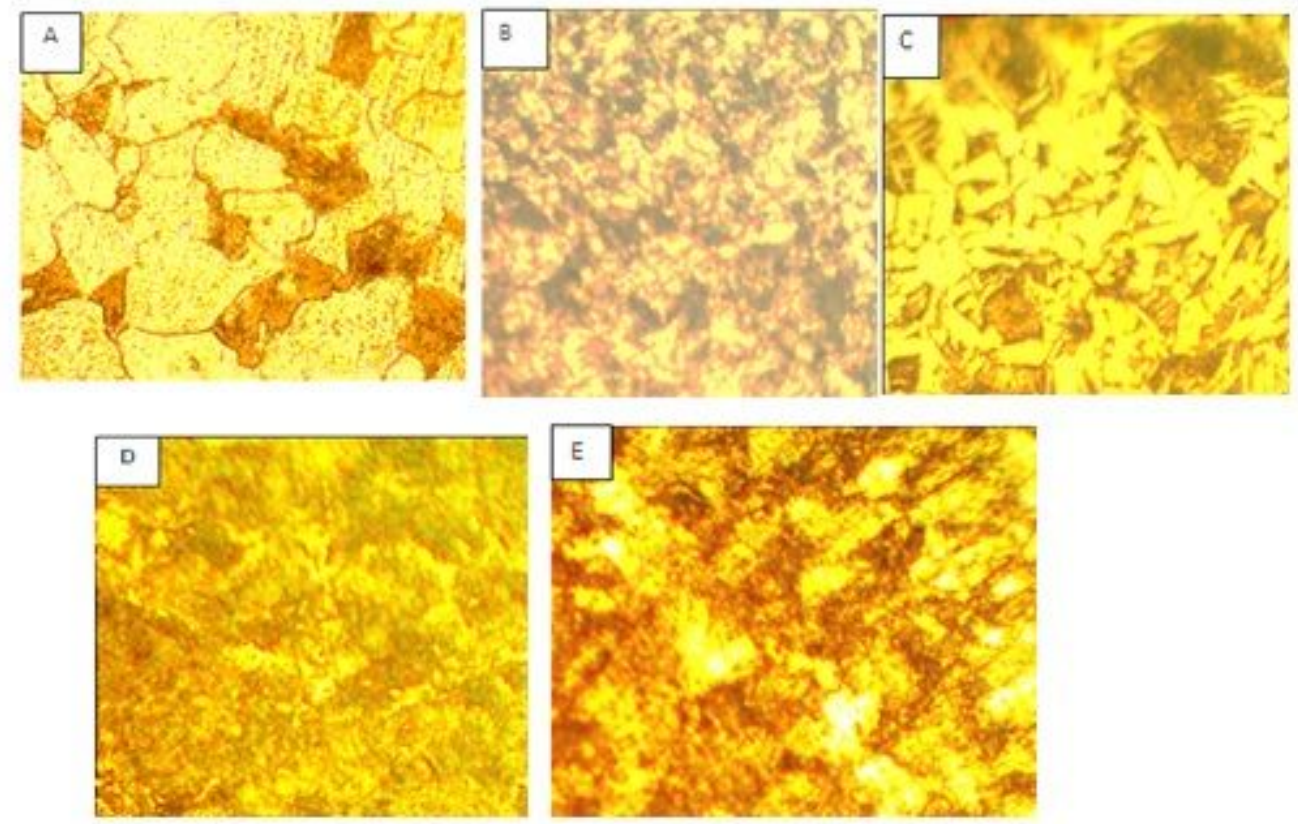

Figure 8

Microstructure of all specimens at $40 \mathrm{X}$ 


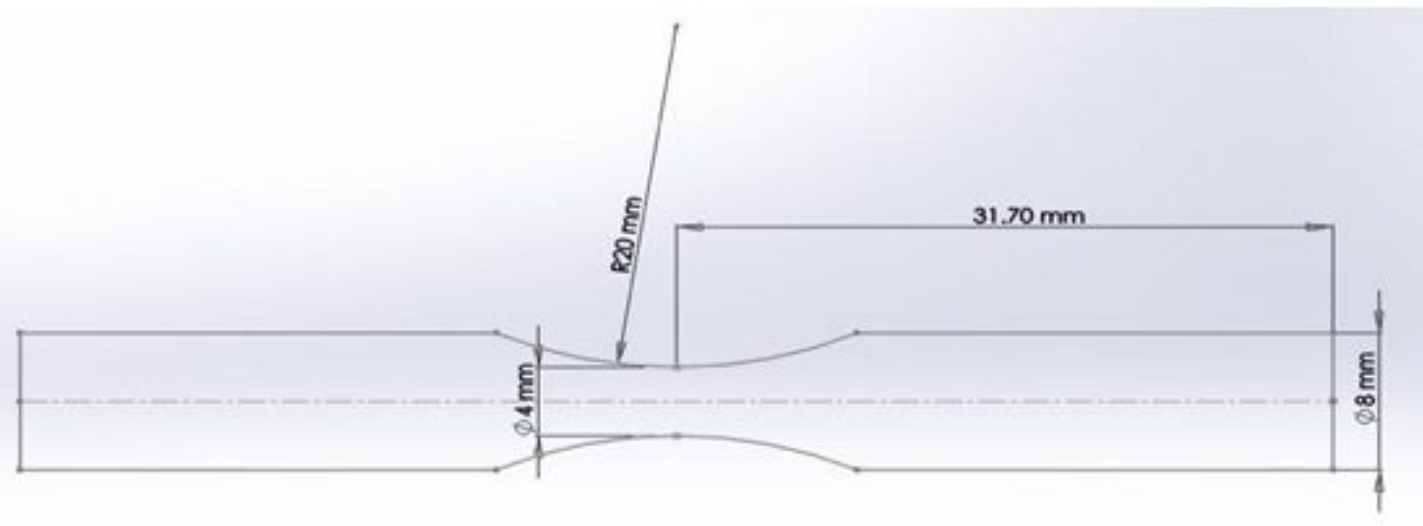

Figure 9

Fatigue test sample in $(\mathrm{mm})$.

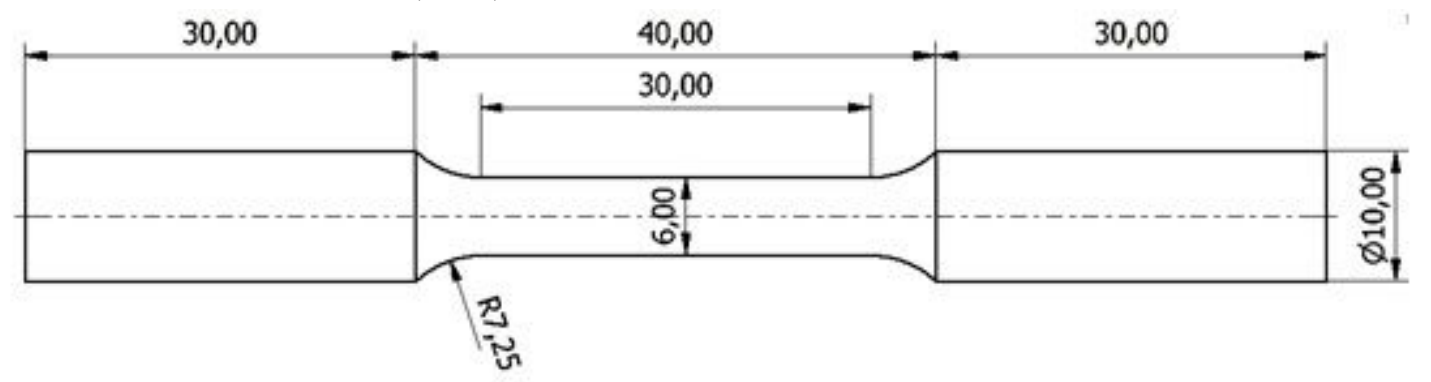

Figure 10

Tensile examination sample with measurements in $(\mathrm{mm})$ 